\title{
Chitosan Membranes Filled with Cyclosporine A as Possible Devices for Local Administration of Drugs in the Treatment of Breast Cancer
}

\author{
Sonia Trombino ${ }^{1}$, Federica Curcio ${ }^{1}$, Teresa Poerio ${ }^{2}{ }^{(}$, Michele Pellegrino ${ }^{1}$, Rossella Russo ${ }^{1}(\mathbb{D}$ \\ and Roberta Cassano ${ }^{1, *(1)}$
}

1 Department of Pharmacy and Health and Nutrition Sciences, University of Calabria, Arcavacata di Rende, 87036 Cosenza, Italy; sonia.trombino@unical.it (S.T.); federica.curcio@unical.it (F.C.); michele.pellegrino@unical.it (M.P.); rossella.russo@unical.it (R.R.)

2 Institute on Membrane Technology (CNR-ITM), University of Calabria, Arcavacata di Rende, 87036 Cosenza, Italy; t.poerio@itm.cnr.it

* Correspondence: roberta.cassano@unical.it; Tel.: +39-984-493227

check for updates

Citation: Trombino, S.; Curcio, F.; Poerio, T.; Pellegrino, M.; Russo, R.; Cassano, R. Chitosan Membranes Filled with Cyclosporine A as Possible Devices for Local Administration of Drugs in the Treatment of Breast Cancer. Molecules 2021, 26, 1889. https://doi.org/ $10.3390 /$ molecules 26071889

Academic Editor: Matthew Bernards

Received: 1 March 2021

Accepted: 23 March 2021

Published: 26 March 2021

Publisher's Note: MDPI stays neutral with regard to jurisdictional claims in published maps and institutional affiliations.

Copyright: (c) 2021 by the authors. Licensee MDPI, Basel, Switzerland. This article is an open access article distributed under the terms and conditions of the Creative Commons Attribution (CC BY) license (https:/ / creativecommons.org/licenses/by/ $4.0 /)$.

\begin{abstract}
The aim of this work is the design, preparation and characterization of membranes based on cyclosporine A (CsA) and chitosan carboxylate (CC) to be used as an implantable subcutaneous medical device for a prolonged therapeutic effect in the treatment of breast cancer. The choice to use CsA is due to literature data that have demonstrated its possible antitumor activity on different types of neoplastic cells. To this end, CsA was bound to CC through an amidation reaction to obtain a prodrug to be dispersed in a chitosan-based polymeric membrane. The reaction intermediates and the final product were characterized by Fourier transform infrared spectroscopy (FT-IR) and proton nuclear magnetic resonance $\left({ }^{1} \mathrm{H}-\mathrm{NMR}\right)$. Membranes were analyzed by differential scanning calorimetry (DSC) and scanning electron microscopy (SEM). The data obtained showed the effective formation of the amide bond between CsA and CC and the complete dispersion of CsA inside the polymeric membrane. Furthermore, preliminary tests, conducted on MDA-MB-231, a type of breast cancer cell line, have shown a high reduction in the proliferation of cancer cells. These results indicate the possibility of using the obtained membranes as an interesting strategy for the release of cyclosporin-A in breast cancer patients.
\end{abstract}

Keywords: membrane; cyclosporine A; chitosan; carboxylated chitosan; breast cancer

\section{Introduction}

Breast cancer is one of the most diffused neoplastic diseases among women, whose therapeutic approach is based on various methods that include surgical removal, chemo- or radiotherapy and treatment with monoclonal antibodies. Innumerable are the side effects deriving from these therapies, and some of them are related to the cytotoxic activity of drugs that act indistinctly both on cancer cells and on healthy ones. The severe side effects, such as nausea, vomiting, diarrhea, mucositis and myelosuppression, decrease the life quality of the patients. One approach to reduce side effects is to localize the drug to tumors and cancer cells. Local administration of anticancer drugs is already clinically applied. [1] In this approach it is beneficial to increase the residence time of a drug at the administration site. This can be achieved through a carrier matrix that remains at the site of administration and releases therapeutic substances in a controlled manner. Examples of systems for local administration are injectable in situ gelling materials [2-4], beads [5], inhalable particles [6-8], nanocarriers that remain at the site of administration [9-11], microneedles [12,13], liquid crystalline phases [14], creams and ointments [15,16] and metal drug releasing implants $[17,18]$. Nowadays, in the literature, it is reported that the use of subcutaneous implants as drug delivery systems allows to prolong the release of drugs 
with different characteristics in various parts of the body [19-21]. Moreover, to be functional, these devices must show a certain biocompatibility with the reference tissues [22,23]. Natural or synthetic polymeric materials are often used, and possess a high degree of biocompatibility, reduced toxicity, and considerable biodegradability [24-26]. For this reason, the aim of this work was to design implantable dense polymeric membranes, able to prolong the release of a drug directly to the site of action, to guarantee a homogeneous distribution of the same and be able to minimize side effects. In this approach, a dense membrane can act as a vector for the prolonged release of a drug when placed in contact with a neoplastic lesion. Dense membranes consist of a dense structure in which the drug can be transported by diffusion under the driving force of a pressure, concentration, or electrical potential gradient. One of the main physical methods to control the release using a polymeric system is membrane permeation controlled (MPC) release. In this system, the drug is incorporated into a polymeric membrane and the rate of drug release depends on its diffusion through the membrane. The drug used in this work was CsA, which is a neutral cyclic polypeptide that is considered a powerful immunosuppressant and used in clinical practice in the prevention and treatment of rejection of organ transplants. For many years it was used as a drug of choice in the topical and systemic treatment of dermatological pathologies (psoriasis, atopic dermatitis, alopecia), of autoimmune ones (lupus), of rheumatoid arthritis and of autoimmune uveitis $[27,28]$. Recent studies have also demonstrated the possible antitumor activity of this molecule on different types of neoplastic cells [29]. The mechanism of action by which CsA inhibits the proliferation of tumor cells is based on an inhibition of their glycolytic process due to the absence of energy. It exerts a down regulation against the enzyme pyruvate kinase $\mathrm{M} 2$, responsible to produce ATP in the final stages of glycolysis [30]. For this reason, as the energy reserves of the cancer cell cease to exist, it is unable to perform the normal functions of the cell cycle, which stops in the G1/S phase, causing cell death. Being a classical immunosuppressant, systemic administration of CsA in patients with breast tumors can compromise the host's anticancer responses and be harmful. Unfortunately, cyclosporine, a lipophilic drug, is characterized by low solubility and consequent poor oral bioavailability. It also has a narrow therapeutic index and therefore the potential to induce renal toxicity. In this context, an effective, non-toxic, stable and patient-friendly formulation may be useful because it could inhibit the proliferation of breast cancer without affecting general immunity and reducing nephrotoxicity. In particular, the local application of cyclosporine appears to be advantageous as it compromises the suppressive function of the regulatory CD4+, CD25+ and Foxp3 T lymphocytes that infiltrate into tumor tissues [30]. However, this drug, due to its high molecular weight, is unable to distribute evenly and penetrate the stratum corneum of the skin and reach the target site unaffected after its administration. In this regard, the polymer used, chitosan, allows the administration of highly lipophilic drugs, such as CsA, not only orally but also topically. [31]. In particular, the chitosan, a natural polymer derived from chitin, causes an increase in the permeability of the epithelial membrane that favors the permanence of the drug at the absorption site and its paracellular transport [32-34]. Specifically, in this work, CsA, after being covalently linked with the carboxylated chitosan, was dispersed inside a polymeric matrix based on chitosan which was subsequently subjected to contact with the target site, facilitating the dispersion of the drug thanks to a high permeability and flow. The reaction intermediates and the final product were characterized by means of Fourier transform infrared spectroscopy and proton nuclear magnetic resonance. The membranes were analyzed by differential scanning calorimetry and scanning electron microscopy. The obtained data showed the effective formation of the amide bond between the CsA and CC and complete dispersion of the CsA inside the polymeric membrane. Preliminary tests conducted on MDA-MB-231, a highly aggressive, invasive and poorly differentiated triple negative breast cancer (TNBC) cell line, have demonstrated antitumor activity considering the high reduction in tumor cell proliferation. 


\section{Results and Discussion}

\subsection{CsACC Synthesis and Characterization}

CsACC was obtained through an amidation reaction that favored the covalent bond between the derivatized CsA and the carboxylated chitosan. Cyclosporin A (1) was initially esterified with bromoacetyl-bromide in the presence of DMAP to form the corresponding ester (2). Subsequently, with the addition of sodium azide in the presence of DMF, the bromine atom was replaced by a azide anion (3) to then be reduced to the amine form after addition of triphenyl phosphine, water, and anhydrous tetrahydrofuran (4). The amino group, in the presence of DIPEA, DCC and EDC, showed the formation of a bond with the CC carboxyl group (5) (Figure 1).

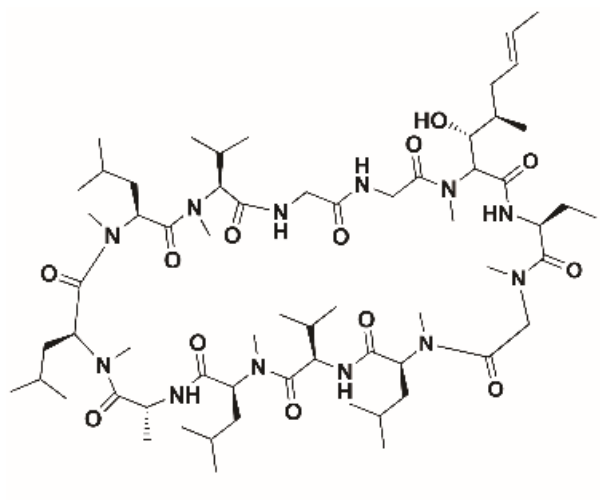

CsA (1)

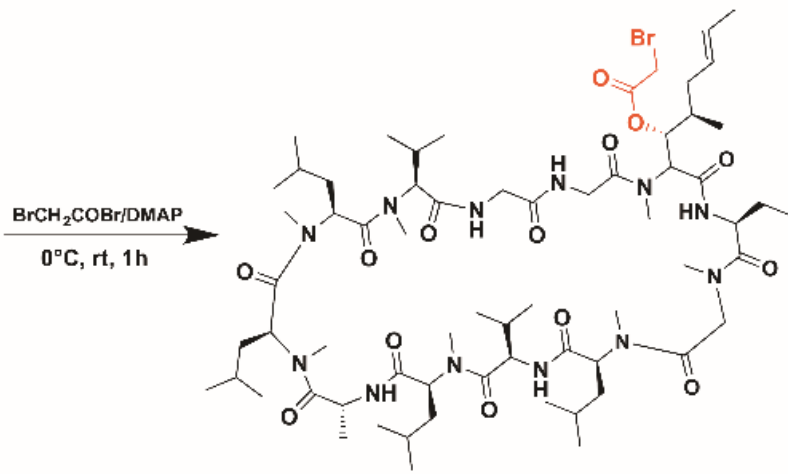

(2)

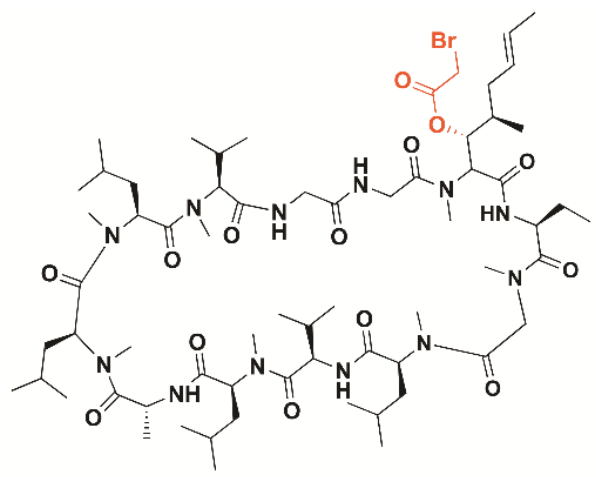

(2)

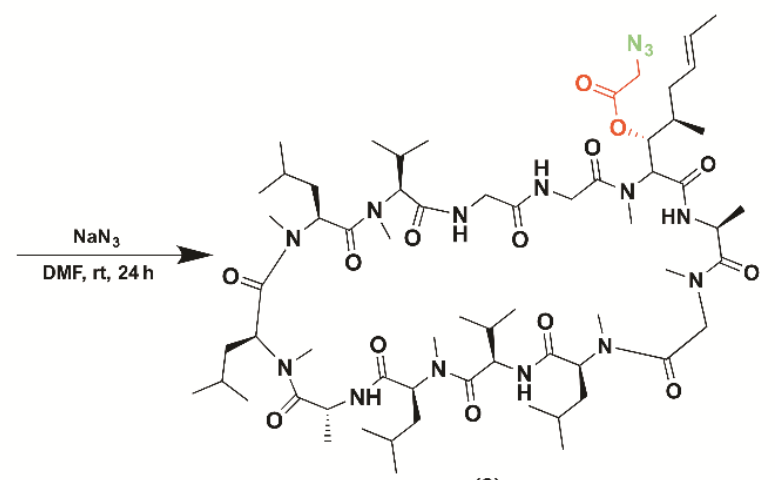

(3)

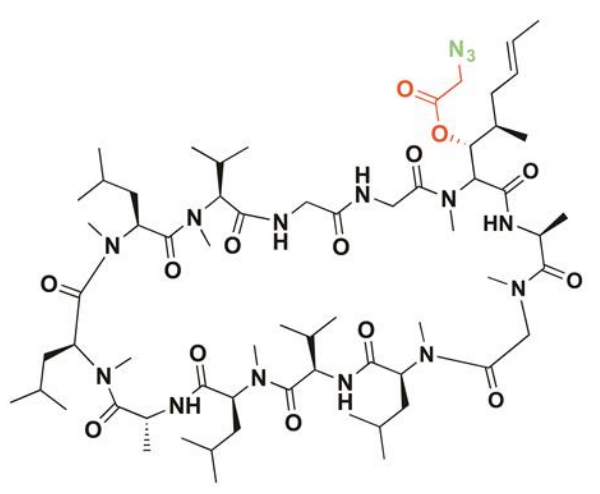

(3)

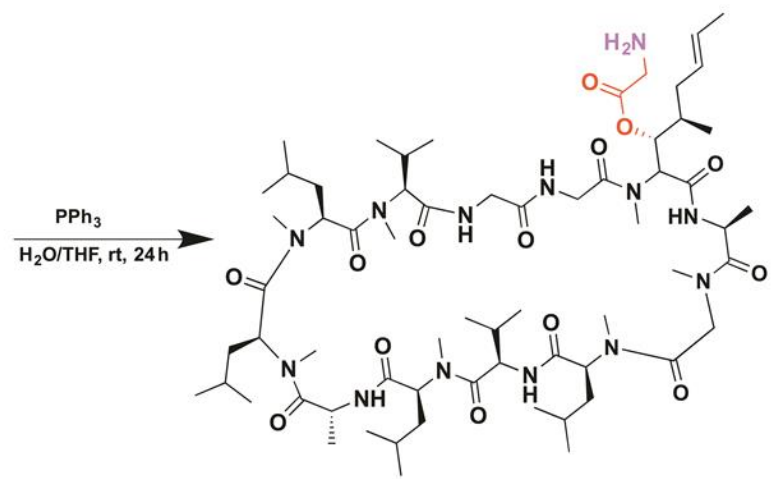

(4)

Figure 1. Cont. 


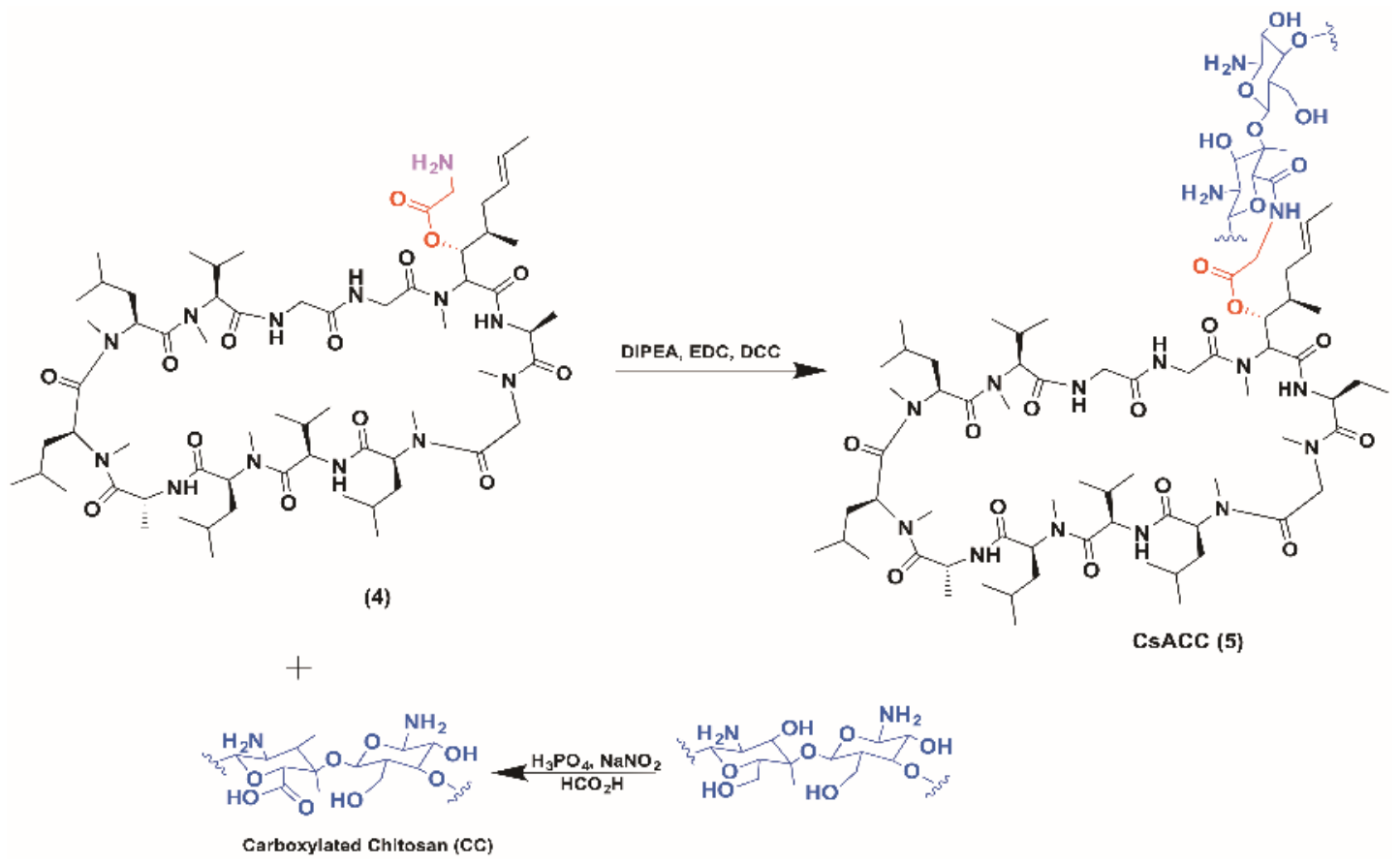

Figure 1. Scheme of CsACC synthesis.

The intermediates of the reaction were characterized. The CC was characterized by spectroscopic techniques. FT-IR $(\mathrm{KBr}) \mathrm{v}\left(\mathrm{cm}^{-1}\right)$ : $3435(\mathrm{OH}), 2925,2855,2833$ (CH aliphatics), 1719(C=O) $1362(\mathrm{OH})$ (Figure 2b). ${ }^{1} \mathrm{H}-\mathrm{NMR}$ (DMSO-d6): 11.2 (bs, 1H), $5.54(\mathrm{~m}, 1 \mathrm{H}), 5.04$ (bs, $2 \mathrm{H}), 4.40(\mathrm{~m}, 1 \mathrm{H}), 3.50(\mathrm{~m}, 1 \mathrm{H}), 3.02(\mathrm{~m}, 1 \mathrm{H}), 2.21(\mathrm{~m}, 1 \mathrm{H})$. Yield: $0.8 \mathrm{~g}$. The CsACC derivate was also characterized by FT-IR and ${ }^{1} \mathrm{H}-\mathrm{NMR}$. FT-IR spectrum shows the presence of a new band at $1621 \mathrm{~cm}^{-1}$ correlated to the stretching vibration of the $\mathrm{C}=\mathrm{O}$ amide (Figure 2a). ${ }^{1} \mathrm{H}-\mathrm{NMR}$ analysis has provided a very broad and complex spectrum in $\mathrm{CDCl}_{3}$ in which the signals of the $\mathrm{N}$-methyl groups (3 ppm) and those related to $\mathrm{CH}_{3}$ in the side chain of different amino acid residues (1 ppm) are evident (Figure 3$)$. In this spectrum, the signals of $\mathrm{CH}_{2}$ and $\mathrm{CH}$ of chitosan between 3-4 ppm are also evident. The DSC curves of the carboxylated chitosan (b) and the CsACC derivative (a) are shown in Figure 4. The CC showed an endothermic peak at $205^{\circ} \mathrm{C}$, the amide derivate at $207^{\circ} \mathrm{C}$, and the CsA (curve not shown) at $244^{\circ} \mathrm{C}$.

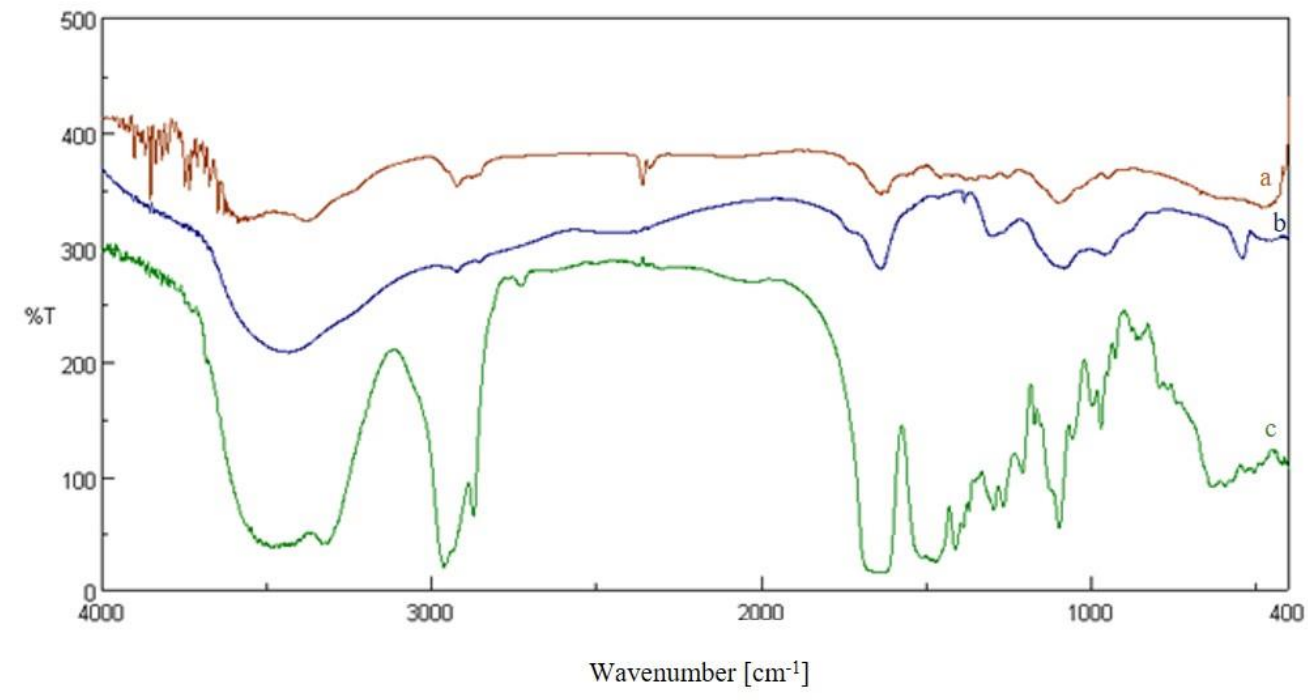

Figure 2. FT-IR of CsACC (a), CC (b), CsA (c). 


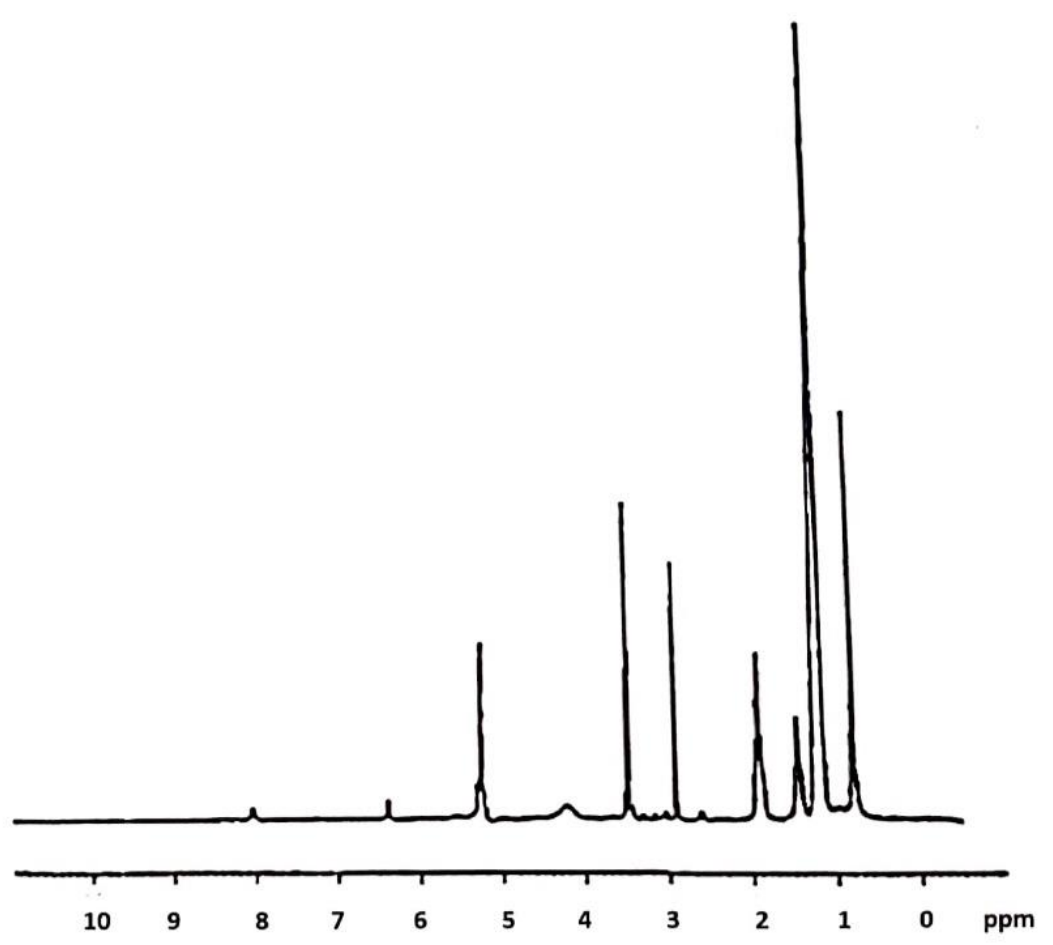

Figure 3. ${ }^{1} \mathrm{H}-\mathrm{NMR}$ spectrum of CsACC.

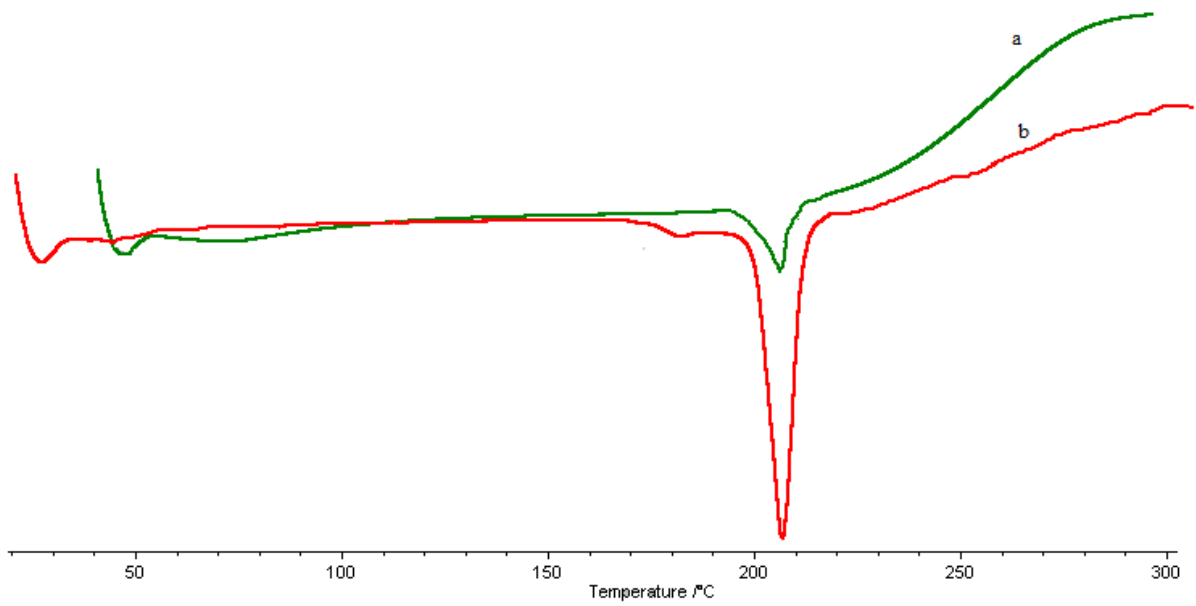

Figure 4. DSC curve of CsACC (a), CC (b).

The membranes were characterized by FT-IR and electronic scanning microscopy (SEM). Characterization by FT-IR revealed that the spectrum of chitosan did not change, despite the composition of the membranes being modified (Figure 5).

\subsection{Characterization of Membranes}

The obtained membranes were characterized by SEM micrographies. The results showed that the membrane based on chitosan (a), and chitosan + CsaCC (b) appear dense. However, from figure (b) is evident the presence of the CsACC derivative that appears like filaments that protrude from the membranes (Figure 6). 


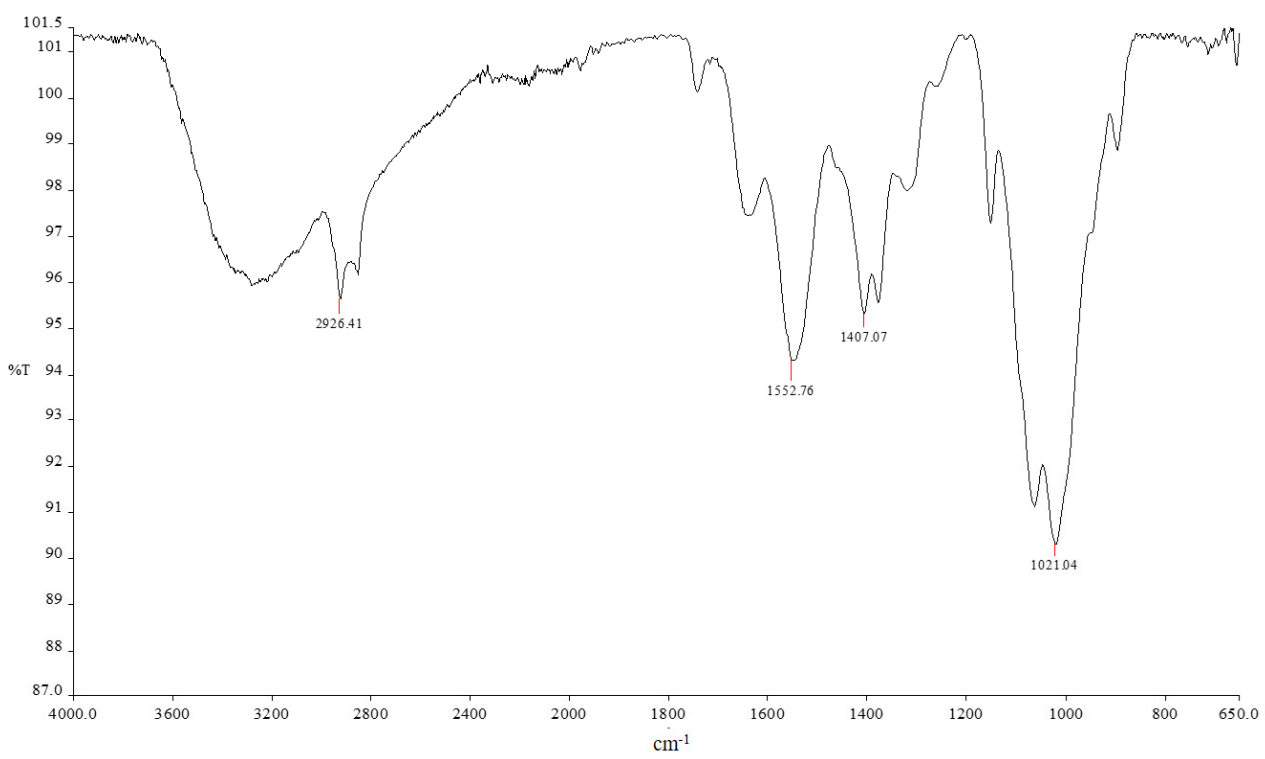

(a)

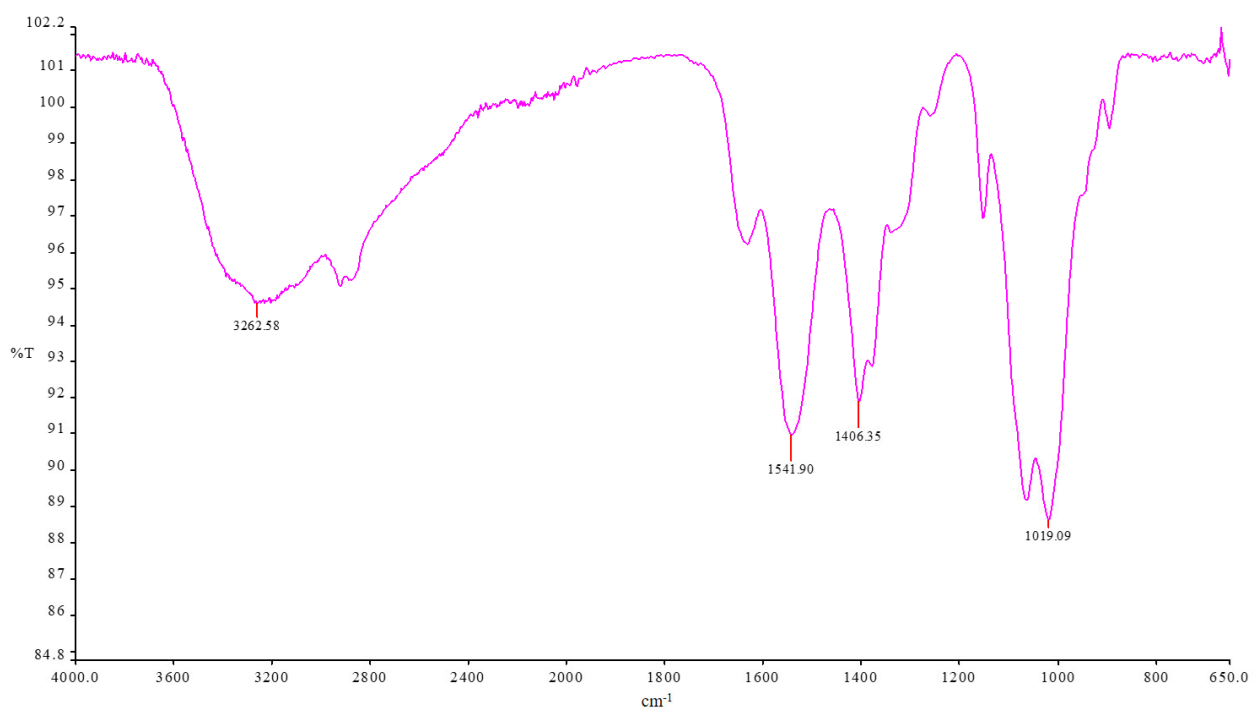

(b)

Figure 5. FT-IR of membrane based on chitosan (a), chitosan + CsACC (b).

\subsection{Skin Permeation Studies}

To have dermatological formulations and further modulate CsA release, this drug and its prodrug were used to obtain various membranes of chitosan that were then subjected to transdermal release studies to evaluate their potential application and efficacy in oncological diseases treatment. Drug release profiles were evaluated by using Franz diffusion cells with membranes or pigskin. Synthetic membranes, in addition to pig skin, were used because cyclosporine is characterized by a specific absorbance range $(\lambda=195-215 \mathrm{~nm})$ and, therefore, can interfere with several skin components, such as lipid and proteins, that adsorb at similar wavelengths $[35,36]$. The presence of skin components in receptor chambers can be attributed to the release medium composition $(0.9 \% \mathrm{NaCl} /$ ethanol $20 \%$ ) since ethanol can promote phospholipid mobility [37]. Ethanol was added to the release medium since cyclosporine is soluble in ethanol but not in water [38]. To further eliminate the risk of possible interferences, a $14 \mathrm{kDa}$ cut-off membrane was used. In fact, 
the obtained data showed, by comparing release studies carried out using pig skin and cellulose acetate membrane, an absence of significant interferences. Drug release studies were performed on dermatological formulations at different time intervals $(1,4,8,12$, and $24 \mathrm{~h}$ ). Drug release profiles were determined by UV-Vis spectrometry and expressed as percentage of the drug released with respect to the total loaded amount as a function of time. Data showed that, with cellulose acetate membrane, cyclosporin A was released within $8 \mathrm{~h}$ from the membranes, in quantities ranging from $0.15 \%$ (membrane CHIT + prodrug) to $0.9 \%$ (membrane CHIT $+\mathrm{CsA}$ ) of the total loaded amount. After $1 \mathrm{~h}$, release was not observed from membrane containing free CsA. Instead, the release from membrane containing the prodrug stopped after $4 \mathrm{~h}$. Studies conducted by means of pig skin revealed a total CsA percentage of $4.2 \%$ for membrane containing the free CsA and of $2.7 \%$ for membrane containing the prodrug, within $24 \mathrm{~h}$. The higher percentage of cyclosporine released using pig skin is probably due to the presence of skin components as previously pointed out. After that, to evaluate if CsA had been released from the membrane in the pig skin, given the low percentage present in the acceptor compartment after carrying out the transdermal release, the chitosan membranes were solubilized and subjected to observation on a UV-Vis spectrophotometer in the range of 195-215 nm. The obtained results revealed the presence of percentage of free CsA and prodrug equal to $21 \%$ and $18 \%$, respectively. This result suggests that the remaining portions are placed in the pig skin used during transdermal birth. To validate this hypothesis, chitosan membranes were also prepared using coumarin-6 as a model drug, being a particularly lipophilic substance in analogy to CsA. An observational skin study was performed to verify how coumarin arranged itself within the pig's skin after transdermal release. Fluorescence microscopy imaging (CLSM) was used to visualize its distribution and penetration depth through the pig skin. As clearly visible in Figure 7, the coumarin-6 was found to be concentrated into the dermis layer of the pig skin after release from membrane containing free CsA as compared to control chitosan membrane. On the other hand, coumarin- 6 released from membrane containing the CsA prodrug was positioned both on the shin surface and in the more internal layer, probably the subcutaneous one. Obtained results represent a starting point. Other studies are required to verify with certainty the effectiveness of the prepared membranes and the release mechanisms of CsA.

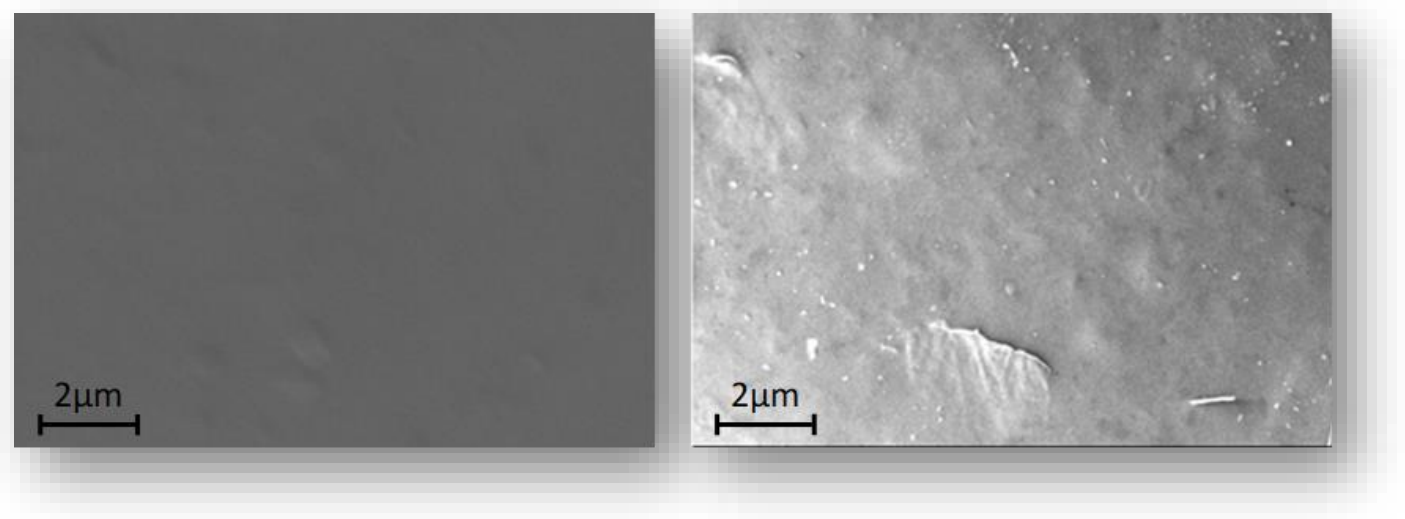

(a)

(b)

Figure 6. SEM photomicrographies of the membrane based on chitosan (a), and chitosan + CsACC (b). The images are taken at $10 \mathrm{~K} \times$ magnification.

\subsection{Cell Proliferation Assays}

The effects of CsACC membranes and CsA free on the viability processes of cellulose in human breast cancer cells MDA-MB-231, were analyzed by cell proliferation assay. At the concentrations used in the experiment, after $72 \mathrm{~h}$ of treatment, significant biological effects 
were observed in our experimental model. In particular, the results obtained showed a significant decrease in cell viability especially in cells treated with CsACC and with chitosan mixed with free CsA. This effect is not observed by treating the cells uniquely with CsA at the same concentration with which it is present in the membranes (Figure 8).

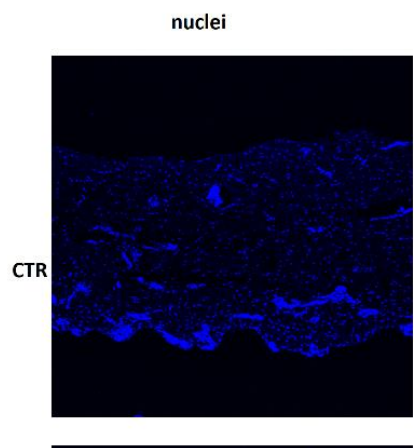

coumarin-6
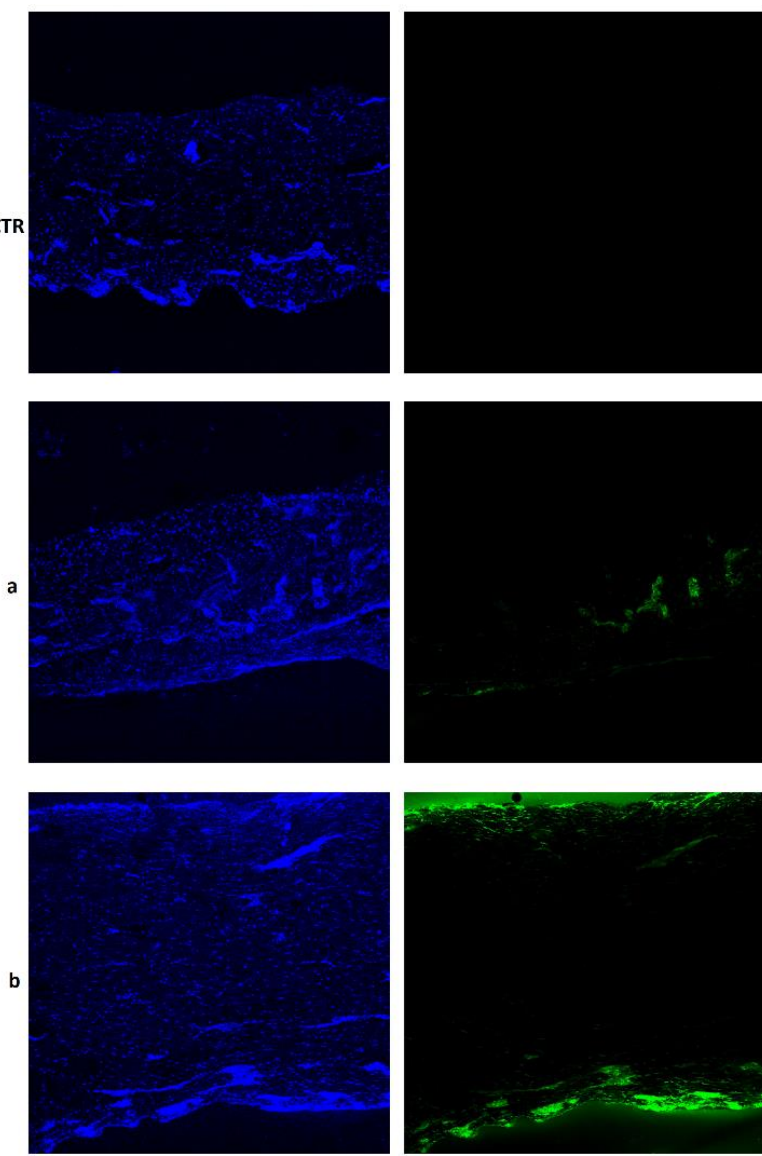
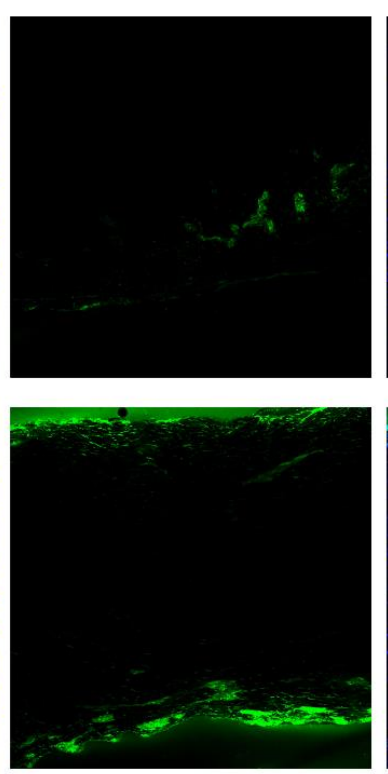

merge
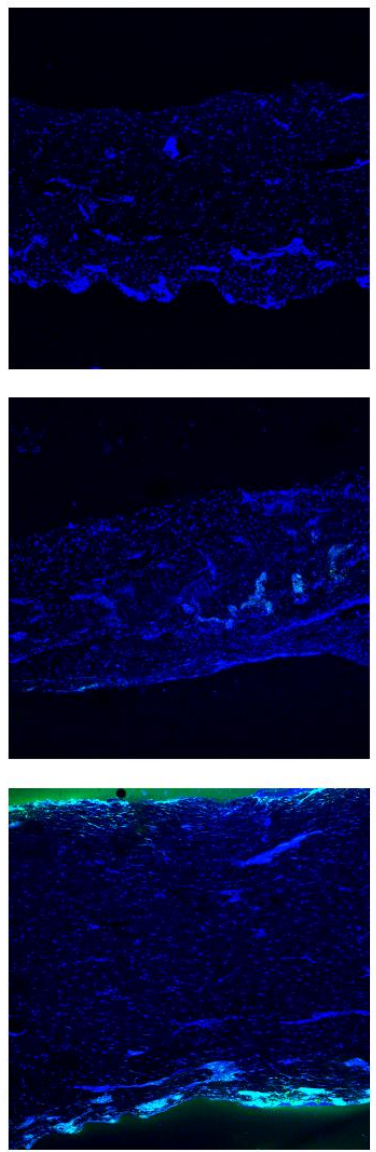

Figure 7. Confocal imagine of chitosan membrane (CTR), membrane based on free CsA containing coumarin-6 (a), and membrane based on CsACC containing cumarin-6 (b).

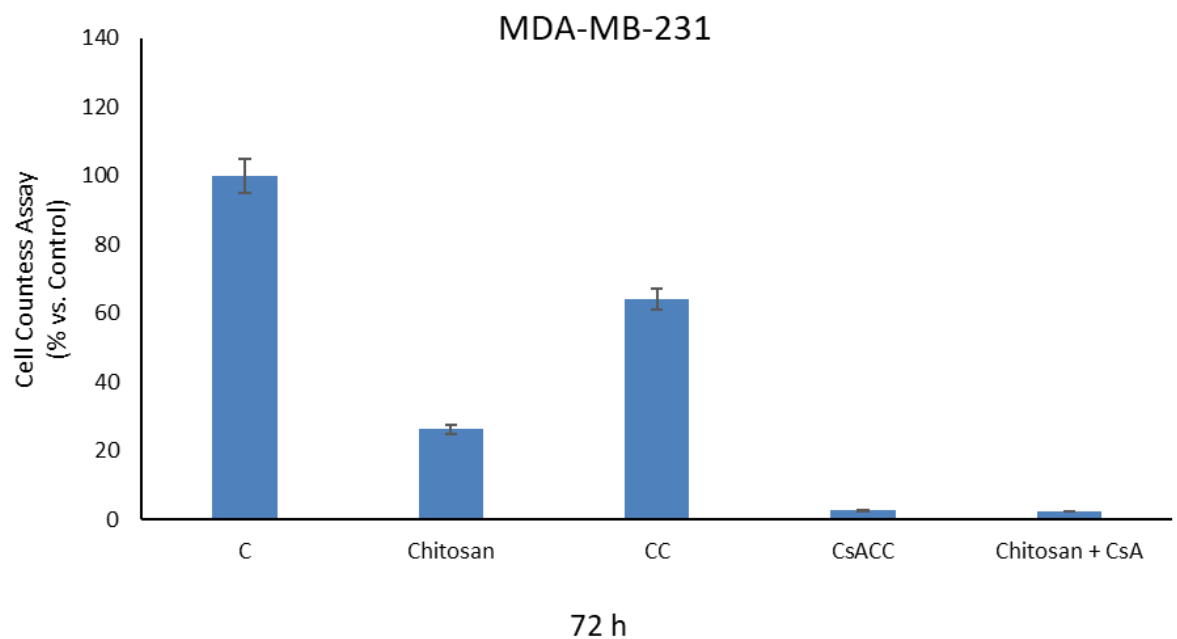

Figure 8. Cell proliferation assay on MDA-MB-231 cell lines of chitosan membranes with and without CsA. 


\section{Materials and Methods}

\subsection{Materials}

For the synthesis of the prodrug, the following materials were used: medium-molecularweight chitosan purchased from Sigma Aldrich (St. Louis, MO, USA), orthophosphoric acid $\left(\mathrm{H}_{3} \mathrm{PO}_{4}\right) 85 \%$ purchased from Carlo Erba Reagenti (Milan, Italy), nitrite of sodium $\left(\mathrm{NaNO}_{2}\right)$, 85\% formic acid, bromoacetyl bromide purchased from Sigma Aldrich, sodium bicarbonate $\left(\mathrm{NaHCO}_{3}\right)$, sodium sulfate $\left(\mathrm{Na}_{2} \mathrm{SO}_{4}\right)$, dimethylaminopyridine (DMAP), dimethylformamide (DMF), phosphate buffer (PBS), sodium azide, diisopropylethylamine (DIPEA), dicyclohexylcarbodiimide (DCC), ethyl 1-3 dimethylaminopropylcarbodiimide (EDC), hydrochloric acid $(\mathrm{HCl})$, sodium chloride $(\mathrm{NaCl})$, and triphenylphosphine purchased from Fluka Chemika-Biochemika (Buchs, Switzerland). The solvents used were: dichloromethane, chloroform, tetrahydrofuran, diethyl ether, ethanol, methanol, acetone and cold ethyl ether, purchased from VWR Chemicals Prolabo (Milano, Italy), Fluka Chemika-Biochemika (Buchs, Switzerland) and LabScan Analytical Sciences (Gliwice, Poland). Methylene blue was purchased from BDH Analytical Chemicals (Ontario, Canada). Ciclosporin (molecular weight $1202.61 \mathrm{~g} / \mathrm{mol}$ ) was purchased from Farmalabor Srl (Bari, Italy). For the preparation of the membranes, the chitosan (average molecular weight) purchased from Aldrich (St. Louis, MO, USA), PVA (Polyvinyl alcohol 13,000-23,000 Dalton, 98\% hydrolyzed, Sigma Aldrich), acetic acid purchased from VWR Chemicals Prolabo, multi-well plates purchased from thermo-scientific (Milano, Italy) and distilled water were used.

\subsection{Cell Culture}

Human breast cancer MDA-MB-231 were acquired from Interlab Cell Line Collection (ICLC, Genova, Italy), where they were authenticated. Cells were stored according to supplier's instructions and used within 6 months after frozen aliquot resuscitations. MDA-MB-231 were cultured in Dulbecco's Modified Eagle's medium-F12 plus glutamax containing 5\% fetal bovine serum (Invitrogen, Carlsbad, CA, USA), and $1 \mathrm{mg} / \mathrm{mL}$ penicillin-streptomycin at $37{ }^{\circ} \mathrm{C}$ with $5 \% \mathrm{CO}_{2}$ air. Mycoplasma negativity was tested monthly (MycoAlert, Lonza, Basel, Switzerland).

\subsection{Instruments}

The 1H-NMR spectra were realized through a Bruker VM 30 spectrophotometer (Bruker, Ettlingen, Germany). The FT-IR spectra were processed through a Jasco 4200 spectrophotometer (Jasco Europe S.R.L, Lecco, Italy). The spectra UV-Vis were recorded with a Jasco V-530 UV/Vis spectrophotometer (Thermo Fisher Scientific, Monza, Italy). Differential scanning calorimetry (DSC) was performed with a DSC 200 PC Netzsch instrument (NETZSCH-Gerätebau GmbH, Verona, Italy). The micrographs of the membranes were carried out using an electronic scanning microscope (SEM) (FELMI-ZFE, Graz, Austria) FEI Quanta 200, FEG (field emission gun) with a 0.5-30 Kv voltage and an EDX Oxford Inca 300 system. The samples were sputtered with gold before the SEM analysis. The solvents were removed using a Buchi Rotavapor R II (Buchi, Cornaredo, Italy), while the lyophilization of some compounds was carried out through an Edwards "Freezing-drying" Micro Modulyo (Thermo Electron Corporation, Gormley, ON, Canada). The evaporation of the membranes and their complete drying were carried out with a stove for vacuum drying (Thermo Fisher Scientific; Waltham; MA; USA).

\subsection{Synthesis of Carboxylated Chitosan (CC)}

In a three-necked flask fitted with a reflux condenser, magnetic stirrer, meticulously flamed under a nitrogen stream (inert atmosphere), $1 \mathrm{~g}$ of chitosan and $40 \mathrm{~mL}$ of $\mathrm{H}_{3} \mathrm{PO}_{4}$ at $85 \%$ were added. After $1 \mathrm{~h}, 3 \mathrm{~g}$ of sodium nitrite $(0.043 \mathrm{~mol})$ were added, and the solution was kept under vigorous stirring for about $5 \mathrm{~min}$. The addition of $3 \mathrm{~g}$ of sodium nitrite $(0.043 \mathrm{~mol})$ was repeated twice more, keeping everything under magnetic stirrer for $1 \mathrm{~h}$ and $15 \mathrm{~min}$. At the end of the third addition, $10 \mathrm{~mL}$ of formic acid was added to neutralize the sodium nitrite excess. The compound was then precipitated with $400 \mathrm{~mL}$ of cold ethyl ether 
and $100 \mathrm{~mL}$ of acetone under stirring for $30 \mathrm{~min}$ and was filtered and washed with distilled $\mathrm{H}_{2} \mathrm{O}$ and ethanol (100 mL). Subsequently, a further washing was carried out with diethyl ether and methanol to obtain a product which was dried under vacuum and characterized by FT-IR [39].

\subsection{Determination of Carboxylic Groups Content}

The carboxylate chitosan $(0.05 \mathrm{~g})$ was suspended in a solution consisting of $2.5 \mathrm{~mL}$ of phosphate buffer ( $\mathrm{pH} 8.0$ ) and $2.5 \mathrm{~mL}$ of aqueous methylene blue solution and then was filtered, acidified with $1 \mathrm{~mL}$ of $\mathrm{HCl} 0.1 \mathrm{~N}$, and added with $8 \mathrm{~mL}$ of distilled water. The determination of the carboxylic groups was performed using a UV-Vis spectrophotometer through a method that involves the analysis of the test sample containing methylene blue. This sample bind carboxyl groups and tends to decrease its concentration within the solution; the resulting amount of unabsorbed methylene blue has been used in the following equation 1 to determine the actual content of carboxyl groups [40]:

$$
\mathrm{mmol} \mathrm{COOH} / \mathrm{g} \text { dry sample }=\frac{(7.5-\mathrm{A}) \times 0.00313}{\mathrm{E}}
$$

$\mathrm{A}=$ non-absorbed amount of methylene blue;

$\mathrm{E}=\mathrm{CC}$ amount in grams.

\subsection{Synthesis of $C S A-C C$}

In a two-necked flask under magnetic stirrer for about $1 \mathrm{~h}, 0.06 \mathrm{~g}\left(4.98 \times 10^{-5} \mathrm{~mol}\right)$ of CsA, $1 \mathrm{~mL}$ of bromoacetyl bromide $(0.013 \mathrm{~mol})$ and $0.03 \mathrm{~g}$ of dimethylaminopyridine $\left(2.45 \times 10^{-4} \mathrm{~mol}\right)$ were added. The progression of the reaction was monitored by TLC (silica gel) using chloroform-methanol (6:4) as eluent mixture. At the same time, an aqueous solution containing $7.5 \mathrm{~mL}$ of distilled water and $1.15 \mathrm{~g}$ of $\mathrm{NaHCO}_{3}(0.0136 \mathrm{~mol})$ was prepared. This last was added to the compound contained in the flask. The two phases were separated by performing an extraction with dichloromethane $(6 \mathrm{~mL})$. After that, the organic phase was treated with $\mathrm{Na}_{2} \mathrm{SO}_{4}$ to remove the residual water, washed with dichloromethane and then filtered. The product was evaporated, lyophilized, characterized to ${ }^{1} \mathrm{H}-\mathrm{NMR}$ to give $0.578 \mathrm{~g}$. Successively, $0.578 \mathrm{~g}\left(4.4 \times 10^{-4} \mathrm{~mol}\right)$ of product were added to $20 \mathrm{~mL}$ of DMF and $0.0310 \mathrm{~g}\left(4.78 \times 10^{-4} \mathrm{~mol}\right)$ of sodium azide, to obtain a solution which was left under magnetic stirrer for $24 \mathrm{~h}$. The mixture was evaporated, and the residue was dispersed in dichloromethane $(60 \mathrm{~mL})$ and washed with an aqueous solution containing $\mathrm{NaCl}$. Then, the organic phase was a hydride with $\mathrm{Na}_{2} \mathrm{SO}_{4}$, filtered and evaporated. The residue was dried and dissolved in $2 \mathrm{~mL}$ of dry tetrahydrofuran under magnetic stirrer. In the mixture, $0.000143 \mathrm{~g}\left(5.45 \times 10^{-7} \mathrm{~mol}\right)$ of tri-phenyl phosphine and $41 \mu \mathrm{L}$ of distilled water were added and stirred for $18 \mathrm{~h}$. The solvent was evaporated, and the obtained residue was dissolved in $100 \mathrm{~mL}$ of ether and in a cold solution of $\mathrm{HCl}$ in ether to facilitate its precipitation. The residue was dissolved in ethyl ether and nhexane, evaporated, frozen and lyophilized. At the obtained product, $125 \mathrm{~mL}$ (1.95 mol) of dichloromethane, $0.37 \mathrm{~mL}\left(2.12 \times 10^{-3} \mathrm{~mol}\right)$ of DIPEA, $0.044 \mathrm{~g}\left(2.83 \times 10^{-4} \mathrm{~mol}\right)$ of EDC, $0.162 \mathrm{~g}\left(7.86 \times 10^{-4} \mathrm{~mol}\right)$ and $0.172 \mathrm{~g}$ of CC were added. The reaction was kept under magnetic stirring for $24 \mathrm{~h}$, then the product was filtered and dried under vacuum [41,42].

\subsection{Preparation of Chitosan (CM) and Membranes Chitosan (CMCsCC) Membranes}

Dense membranes consist of dense structure presenting no detectable pore at the limits of electron microscopy. A mixture of molecules is transported through dense membranes by diffusion under the driving force of a pressure, concentration, or electrical potential gradient. Dense membranes may have a symmetric or an asymmetric structure. Dense membranes were prepared by phase inversion induced by solvent evaporation. A mixture of $0.15 \mathrm{~g}$ of chitosan in $5 \mathrm{~mL}$ of acetic acid solution (3\%) was stirred for $24 \mathrm{~h}$ in a vial placed inside an oil bath at $40^{\circ} \mathrm{C}$. One milliliter of this solution was then placed 
in a multi-well plates and dried at $80{ }^{\circ} \mathrm{C}$ for $4 \mathrm{~h}$ [43]. Table 1 shows other examples of membranes made with this procedure.

Table 1. Membranes based on chitosan and other components.

\begin{tabular}{cccc}
\hline Membranes & Chitosan & Acetic Acid Solution $(\mathbf{m L})$ & Csacc $(\mathrm{g})$ \\
\hline $\mathrm{CM}{ }^{* 1}$ & $0.15 \mathrm{~g}$ & $5 \mathrm{~mL}$ & - \\
\hline $\mathrm{CM}{ }^{* 2}+$ Csacc & $0.15 \mathrm{~g}$ & $5 \mathrm{~mL}$ & $0.017 \mathrm{~g}$ \\
\hline${ }^{* 1}$ Chitosan Membranes. ${ }^{* 2}$ Chitosan Membranes + Ciclosporine A-Carboxylated Chitosan. &
\end{tabular}

\subsection{In Vitro Skin Permeation Studies}

Skin permeation studies were performed by using Franz diffusion cells apparatus with cellulose acetate membranes and pig skin (furnished from local butcher) for $24 \mathrm{~h}$. The apparatus was maintained at $37^{\circ} \mathrm{C}$ to mimic physiological conditions. Receptor chambers $(7.0 \mathrm{~mL})$ were filled with $\mathrm{NaCl} 0.9 \%$ solution containing ethanol $(20 \%)$ and kept under stirring. Unloaded chitosan membranes were used as control. At specific time intervals $(1,2,4,8,10$, and $24 \mathrm{~h})$ an aliquot $(1 \mathrm{~mL})$ of each sample was withdrawn from receptor chambers and replaced with fresh release medium. Samples were analyzed through UV-Vis spectrophotometry and drug release profiles were expressed as percentage of drug released respective to the total loaded amount in function of time.

\subsection{Localization of CsA in Skin (CLSM Study)}

Confocal laser scanning microscopy (CLSM) (Leica Microsystems Srl, Milan, Italy) was carried out to see the depth of permeation of a fluorescent lipophilic substance as a model drug like coumarine-6. The dye loaded membranes were applied on the pig skin and kept for $24 \mathrm{~h}$ in the permeation experiment. At the end of the experiment, the excess formulation was removed from the skin surface. The skin was washed 3 times with phosphate buffer ( $\mathrm{pH}$ 7.4) and dried. Specimens were embedded in optimal cutting temperature compound (Tissue-Tek, Sakura Finetek Europe, Alphen aan den Rijin, The Netherlands) and stored at $-80{ }^{\circ} \mathrm{C}$. Cryostat-cut skin sections ( $16 \mu \mathrm{m}$ thick) were mounted on slides and nuclei counterstained with Vectashield solution containing $1.5 \mu \mathrm{g} / \mathrm{mL}$ 4',6-diamidino2-phenylindole (DAPI; Vector Laboratories, Burlingame, CA, USA). Images were acquired using a confocal microscope (Leica TC-SP2 Confocal System, Leica Microsystem Srl, Milan, Italy).

\subsection{Cell Proliferation Assays}

MDA-MB-231 cells were seeded, in triplicate, in 6-well plates in a regular growth medium. On the second day, the cells were synchronized in serum free media (SFM) for $24 \mathrm{~h}$, so that most of the cells belonged to a population in the same cell cycle phase, to avoid growth differences among cells. The following day, cells were put in contact with chitosan, CsA, carboxylated chitosan, CsACC and membrane based on chitosan + CsACC. After $72 \mathrm{~h}, \mathrm{MDA}-\mathrm{MB}-231$ cells were harvested by trypsinization and collected in Eppendorf. All collected samples were incubated in a $0.5 \%$ trypan blue solution for $1 \mathrm{~min}$ at room temperature. Cell viability was determined by Countess Automated Cell Counter (NucleoCounter®NC-202, Gydevang, Denmark) [44].

\section{Conclusions}

The present work aimed to design and realize CsACC-based membranes that were potentially useful in the treatment of breast cancer in the form of subcutaneous implants. The membranes obtained were prepared starting from the polymeric product based on carboxylated chitosan and cyclosporin A. Such precursor was obtained by reaction of amidation of the active principle with the previous carboxylated chitosan and characterized by FT-IR and DSC. In vitro permeation studies showed that membranes could potentially release the cyclosporin-A in the skin internal layers. In addition, membranes containing both CsACC membranes and free CsA showed a significant decrease in human breast cancer 
MDA-MB-231 cell viability. This effect is not observed by treating the cells uniquely with free CsA at the same concentration with which it is present in the membranes. Therefore, the obtained membranes could be an interesting strategy for the delivery of cyclosporin-A in patients affected by breast cancer to limit its systemic toxicity.

Author Contributions: S.T., F.C. and R.C conceived, designed the project. S.T., F.C., R.C., T.P., R.R. and M.P. have carried out the experiments. Writing manuscript: S.T., F.C. and R.C. All authors have read and agreed to the published version of the manuscript.

Funding: This research received no external funding.

Institutional Review Board Statement: Not applicable.

Informed Consent Statement: Not applicable.

Data Availability Statement: Not applicable.

Conflicts of Interest: The authors declare no conflict of interest.

Sample Availability: Samples of the compounds are available from the authors.

\section{References}

1. Budker, V.G.; Monahan, S.D.; Subbotin, V.M. Loco-regional cancer drug therapy: Present approaches and rapidly reversible hydrophobization (RRH) of therapeutic agents as the future direction. Drug Discov. Today 2014, 19, 1855-1870. [CrossRef] [PubMed]

2. Chou, H.S.; Larsson, M.; Hsiao, M.H.; Chen, Y.C.; Röding, M.; Nydén, M.; Liu, D.M. Injectable insulin-lysozyme-loaded nanogels with enzymatically-controlled degradation and release for basal insulin treatment: In vitro characterization and in vivo observation. J. Control. Release 2016, 224, 33-42. [CrossRef] [PubMed]

3. Hsiao, M.H.; Chiou, S.H.; Larsson, M.; Hung, K.H.; Wang, Y.L.; Liu, C.J.; Liu, D.M. A temperature-induced and shear-reversible assembly of latanoprost-loaded amphiphilic chitosan colloids: Characterization and in vivo glaucoma treatment. Acta Biomater. 2014, 10, 3188-3196. [CrossRef]

4. Mathew, A.P.; Uthaman, S.; Cho, K.H.; Cho, C.S.; Park, I.K. Injectable hydrogels for delivering biotherapeutic molecules. Int. J. Biol. Macromol. 2018, 110, 17-29. [CrossRef]

5. Rossi, S.M.; Murray, T.; McDonough, L.; Kelly, H. Loco-regional drug delivery in oncology: Current clinical applications and future translational opportunities. Expert. Opin. Drug Deliv. 2020. [CrossRef] [PubMed]

6. Xu, C.; Wang, P.; Zhang, J.; Tian, H.; Park, K.; Chen, X. Pulmonary codelivery of doxorubicin and siRNA by pH-sensitive nanoparticles for therapy of metastatic lung cancer. Small 2015, 11, 4321-4333. [CrossRef] [PubMed]

7. Sharma, P.; Mehta, M.; Dhanjal, D.S.; Kaur, S.; Gupta, G.; Singh, H.; Thangavelu, L.; Rajeshkumar, S.; Tambuwala, M.; Bakshi, H.A.; et al. Emerging trends in the novel drug delivery approaches for the treatment of lung cancer. Chemico-Biol. Interact. 2019, 309, 108720. [CrossRef]

8. Lee, H.-Y.; Mohammed, K.A.; Nasreen, N. Nanoparticle-based targeted gene therapy for lung cancer. Am. J. Cancer Res. 2016, $6,1118-1134$.

9. Ruan, R.; Chen, M.; Sun, S.; Wei, P.; Zou, L.; Liu, J.; Gao, D.; Wen, L.; Ding, W. Topical and targeted delivery of siRNAs to melanoma cells using a fusion peptide carrier. Sci. Rep. 2016, 6, 29159. [CrossRef]

10. Fahmy, H.M.; Saad, E.A.E.M.S.; Sabra, N.M.; Sabra, N.M.; El-Gohary, A.A.; Mohamed, F.F.; Gaber, M.H. Treatment merits of Latanoprost/Thymoquinone-Encapsulated liposome for glaucomatus rabbits. Int. J. Pharm. 2018, 548, 597-608. [CrossRef]

11. Woodrow, K.A.; Cu, Y.; Booth, C.J.; Saucier-Sawyer, J.K.; Wood, M.J.; Saltzman, W.M. Intravaginal gene silencing using biodegradable polymer nanoparticles densely loaded with small-interfering RNA. Nat. Mater. 2009, 8, 526-533. [CrossRef]

12. Wang, C.; Ye, Y.; Hochu, G.M.; Sadeghifar, H.; Gu, Z. Enhanced cancer immunotherapy by microneedle patch-assisted delivery of anti-PD1 antibody. Nano Lett. 2016, 16, 2334-2340. [CrossRef]

13. Tang, T.; Deng, Y.; Chen, J.; Zhao, Y.; Yue, R.; Choy, K.W.; Wang, C.C.; Du, Q.; Xu, Y.; Han, L.; et al. Local administration of siRNA through microneedle: Optimization, bio-distribution, tumor suppression and toxicity. Sci. Rep. 2016, 6, 30430. [CrossRef]

14. Depieri, L.V.; Borgheti-Cardoso, L.N.; Campos, P.M.; Otaguiri, K.K.; de Carvalho Vicentini, F.T.; Lopes, L.B.; Fonseca, M.J.; Bentley, M.V. RNAi mediated IL-6 In vitro knockdown in psoriasis skin model with topical siRNA delivery system based on liquid crystalline phase. Eur. J. Pharm. Biopharm. 2016, 105, 50-58. [CrossRef] [PubMed]

15. Cullen, J.K.; Simmons, J.L.; Parsons, P.G.; Boyle, G.M. Topical treatments for skin cancer. Adv. Drug Deliv. Rev. 2020, $153,54-64$. [CrossRef] [PubMed]

16. Ritprajak, P.; Hashiguchi, M.; Azuma, M. Topical application of cream-emulsified CD86 siRNA ameliorates allergic skin disease by targeting cutaneous dendritic cells. Mol. Ther. 2008, 16, 1323-1330. [CrossRef] [PubMed]

17. Gulati, K.; Aw, M.S.; Losic, D. Nanoengineered drug-releasing Ti wires as an alternative for local delivery of chemotherapeutics in the brain. Int. J. Nanomed. 2012, 7, 2069-2076. 
18. Kaur, G.; Willsmore, T.; Gulati, K.; Zinonos, I.; Wang, Y.; Kurian, M.; Hay, S.; Losic, D.; Evdokiou, A. Titanium wire implants with nanotube arrays: A study model for localized cancer treatment. Biomaterials 2016, 101, 176-188. [CrossRef] [PubMed]

19. Kumar, A.; Pillai, J. Implantable drug delivery systems: An overview. In Nanostructures for the Engineering of Cells, Tissues and Organs, 1st ed.; Grumezescu, A.M., Ed.; Elsevier: Amsterdam, The Netherlands, 2018; Chapter 18; pp. 473-511. ISBN 9780128136652.

20. Benchetrit, S. Implantable Device for Injecting Medical Substances. U.S. Patent US 6,878,137, 12 April 2005.

21. Arps, J. Implantable drug delivery devices. Pro. Med. Pharma. 2013, 1, 22.

22. Park, H.; Park, K. Biocompatibility issues of implantable drug delivery systems. Pharm. Res. 1996, 13, 1770-1776. [CrossRef] [PubMed]

23. Fournier, E.; Passirani, C.; Montero-Menei, C.N.; Benoi, J.P. Biocompatibility of implantable synthetic polymeric drug carriers: Focus on brain biocompatibility. Biomaterials 2003, 24, 3311-3331. [CrossRef]

24. Bhatt, P.; Trehan, S.; Inamdar, N.; Mourya, V.K.; Misra, A. Polymers in Drug Delivery: An Update. In Applications of Polymers in Drug Delivery, 2nd ed.; Misra, A., Shahiwala, A., Eds.; Elsevier: Amsterdam, The Netherlands, 2021; Chapter 2; pp. 1-42. ISBN 9780128196595.

25. Caillol, S. Special Issue "Natural Polymers and Biopolymers II". Molecules 2021, 26, 112. [CrossRef]

26. Ottenbrite, R.M.; Kim, S.W. Polymeric Drugs, and Drug Delivery Systems, 1st ed.; CRC Press: Boca Raton, FL, USA, 2019.

27. Amber, T.; Tabassum, S. Cyclosporin in dermatology: A practical compendium. Dermatol. Ther. 2020, 33, e13934. [CrossRef]

28. Prodanovic, E.M.; Korman, N.J. Traditional systemic therapy: Metrotexate and cyclosporine. In Treatment of Psoriasis; Birkhäuser: Verlag, Switzerland, 2008; pp. 108-120.

29. Dittmar, J.; Rothstein, R.J.; Reid, R.J.D.; Parsons, R.; Maurer, M.; Shaw, J.; Du, X. Methods to Treat Cancer Cyclosporine and Cyclosporine Derivates. U.S. Patent WO2012145427A1, 26 October 2012.

30. Jiang, K.; He, B.; Lai, L.; Chen, Q.; Liu, Y.; Guo, Q.; Wang, Q. Cyclosporine a inhibits breast cancer cell growth by downregulating the expression of pyruvate kinase subtype M2. Int. J. Mol. Med. 2012, 30, 302-308. [CrossRef] [PubMed]

31. Sun, J.; Jiang, G.; Wang, Y.; Ding, F. Thermosensitive Chitosan Hydrogel for Implantable Drug Delivery: Blending PVA to Mitigate Body Response and Promote Bioavailability. J. Appl. Polym. Sci. 2012, 125, 2092-2101. [CrossRef]

32. Islam, M.M.; Shahruzzaman, M.; Biswas, S.; Sakib, M.N.; Rashid, T.U. Chitosan based bioactive materials in tissue engineering applications-A review. Bioact. Mater. 2020, 5, 164-183. [CrossRef]

33. Peptu, C.; Humelnicu, A.C.; Rotaru, R.; Fortuna, M.E. Chitosan-based drug delivery systems. In Chitin and Chitosan: Properties and Applications, 1st ed.; van den Broek, L.A.M., Boeriu, C.G., Eds.; John Wiley \& Sons Ltd.: New York, NY, USA, 2019.

34. Denbanks, E.B.; Ottenbrite, R.M. Perspectives on: Chitosan Drug Delivery Systems Based on their Geometries. J. Bioact. Compat. Polym. 2006, 21, 351-368.

35. Yee, G.C.; Gmur, D.J.; Kennedy, M.S. Liquid-chromatographic determination of cyclosporine in serum with use of a rapid extraction procedure. Clin. Chem. 1982, 28, 2269-2271. [CrossRef]

36. Frei, R.W.; Zech, K. Selective Sample Handling and Detection in High-Performance Liquid Chromatography; Frel, R.W., Zech, K., Eds.; Elsevier: Amsterdam, The Netherlands, 1988; p. 457.

37. Moore, T.; Croy, S.; Mallapragada, S.; Pandit, N. Experimental investigation and mathematical modeling of Pluronic $® F 127$ gel dissolution: Drug release in stirred systems. J. Control. Release 2000, 67, 191-202. [CrossRef]

38. Pose-Vilarnovo, B.; Rodríguez-Tenreiro, C.; dos Santos, J.F.R.; Vázquez-Doval, J.; Concheiro, A.; Alvarez-Lorenzo, C.; Torres-Labandeira, J.J. Modulating drug release with cyclodextrins in hydroxypropyl methylcellulose gels and tablets. J. Control. Release 2004, 94, 351-363. [CrossRef] [PubMed]

39. Cassano, R.; Di Gioia, M.L.; Mellace, S.; Picci, N.; Trombino, S. Hemostatic gauzed based on chitosan and hydroquinone: Preparation, characterization and blood coagulation evaluation. J. Mater. Sci. Mater. Med. 2017, 28, 190. [CrossRef] [PubMed]

40. Cassano, R.; Trombino, S.; Bloise, E.; Muzzalupo, R.; Iemma, F.; Chidichimo, G.; Picci, N. New broom fiber (Spartiumjunceum L.) derivatives: Preparation and characterization. J. Agric. Food Chem. 2007, 55, 9489-9495. [CrossRef] [PubMed]

41. Hamel, A.R.; Hubler, F.; Carrupt, A.; Wenger, R.M.; Mutter, M. Cyclosporine A prodrug: Design, synthesis, and biophysical properties. J. Pept. Res. 2004, 63, 147-154. [CrossRef] [PubMed]

42. Foley, D.W.; Bermudez, I.; Baileys, P.D.; Meredith, D. A cyclosporine derivative is a substrate of the oligopeptide transporter PepT1. Med. Chem. Commun. 2016, 7, 999-1002. [CrossRef]

43. Clasen, C.; Wilhelms, T.; Kulicke, W.M. Formation and characterization of chitosan membranes. Biomacromolecules 2006, 7, 3210-3222. [CrossRef]

44. Cirillo, F.; Pellegrino, M.; Malivindi, R.; Rago, V.; Avino, S.; Muto, L.; Dolce, V.; Vivacqua, A.; Rigiracciolo, D.C.; De Marco, P.; et al. GPER is involved in the regulation of the estrogen-metabolizing CYP1B1 enzyme in breast cancer. Oncotarget 2017, 8, 106608-106624. [CrossRef] 